\title{
PRIORIDADES SOCIOAMBIENTAIS EM BAIRROS DE GOIÂNIA-GOIÁS
}

\section{SOCIAL AND ENVIRONMENTAL PRIORITIES IN NEIGHBORHOODS OF GOIÂNIA-GOIÁS}

\author{
Fernando Negret Fernandez \\ Faculdades Alves Faria - Goiânia - GO - Brasil \\ Elimar Pinheiro do Nascimento \\ Universidade de Brasília - Brasília - DF - Brasil
}

Resumo: O objeto deste artigo são as prioridades socioambientais em bairros pobres. Consideram-se prioridades socioambientais os aspectos materiais e imateriais que determinam as condições de vida digna da população e que, portanto, devem ser atendidos e supridos em primeira instância. Esta pesquisa consultou as prioridades nos oito bairros mais pobres da cidade de Goiânia, capital de Goiás, conforme informação fornecida pelo Instituto Mauro Borges-IMB. Goiânia é uma cidade planejada, mas que sofreu acelerada urbanização e ocupação desordenada, causada, principalmente, pela construção de Brasília e ocupação do cerrado pelo agronegócio. A pesquisa foi feita com as lideranças locais e os agentes sociais representativos dos bairros selecionados. Foram realizadas dez entrevistas em cada bairro e definidas as prioridades socioambientais de seus locais de moradia. Para cada bairro foram definidas três prioridades principais, totalizando onze comuns. A conclusão mais imediata é a de que segurança e saúde são as prioridades com maior reivindicação, o que coincide com as demandas em outras cidades brasileiras.

Palavras-chave: Bairros. Prioridades sociais. Prioridades ambientais.

Abstract: The aim of this study are the socioenvironmental priorities in poor neighborhoods. The socioenvironmental priorities are considered as the material and immaterial aspects which determine the decent life conditions of the population and, therefore, they need to be attended and supplied in the first instance. This research consulted the priorities in eight poor neighborhoods of the city of Goiânia, Goiás capital, according to the information provided by the Instituto Mauro Borges. Goiânia is a planned city but suffered an accelerated urbanization and a disorganized occupation caused, mainly, by Brasília's construction and the Cerrado's occupation by agribusiness. The research was developed with the local leaderships and the social representative agents of the selected neighborhoods. There were conducted ten interviews in each neighborhood and defined the socialenvironmental priorities of their 
residence areas. For each neighborhood were defined three main priorities, numbering eleven priorities in common. The most immediate conclusion is that seciurity and health are the most claimed priorities, which coincide with the demands of other Brazilian cities.

Keywords: Neighborhoods. Social priorities. Environmental priorities.

\section{INTRODUÇÃO}

O presente artigo é resultado de pesquisa realizada para determinar as prioridades socioambientais em oito bairros considerados os mais pobres de Goiânia, capital de Goiás. São consideradas prioridades socioambientais as necessidades básicas insatisfeitas que uma sociedade ou grupo social considera indispensáveis para uma vida digna. No caso desses bairros, foram assinaladas como prioritárias, pelas lideranças e outras pessoas-chave entrevistadas, a segurança pública, os serviços de saúde, a educação, o saneamento básico, o transporte e o comércio local para insumos domésticos, entre outros.

A pesquisa foi realizada, inicialmente, no âmbito do mestrado em desenvolvimento regional das Faculdades Alfa de Goiânia e teve a colaboração dos alunos desse programa no trabalho de campo para a coleta das informações. Os discentes realizaram as entrevistas com pessoas-chave previamente escolhidas dentre as lideranças comunitárias mais ativas na vida social dessas localidades. Posteriormente, foram obtidas informações complementares em órgãos da prefeitura de Goiânia e instituições municipais.

Este artigo, ademais dessa introdução e da conclusão, está estruturado em sete itens. O primeiro define o objeto de investigação, que são as prioridades socioambientais nos oito bairros goianos selecionados como os mais pobres de acordo com os dados do IMB. $O$ segundo item consiste na definição da problemática da pesquisa e suas implicações teóricas. O terceiro, descreve os procedimentos metodológicos utilizados na pesquisa. O quarto, apresenta um breve histórico do desenvolvimento urbano de Goiânia marcado pela desigualdade. O quinto item descreve a origem e a organização social dos bairros selecionados para a pesquisa. $O$ sexto apresenta o resultado das definições realizadas pela população inquerida quanto às prioridades socioambientais de seu bairro. E o último item trata da análise dos resultados da pesquisa. 


\section{OBJETO DE INVESTIGAÇÃO}

A investigação tem como objetivo identificar as prioridades socioambientais nos seguintes bairros de Goiânia: Conjunto Habitacional Baliza; Conjunto Madre Germana II; Jardim Lajeado; Residencial Belo Horizonte; Residencial Irisville; Residencial Privê das Oliveiras; Residencial Real Conquista; e Vila Fim Social.

Esses bairros foram considerados os mais pobres da cidade de Goiânia pelo IMB da Secretaria de Estado de Gestão e Planejamento do Governo de Goiás-SEGPLAN, segundo as deficiências em serviços públicos, equipamentos sociais e transporte. Eles estão localizados nos seguintes setores da cidade: quatro no Sudeste, três no Noroeste e um na região mais central da cidade (Figura 1). Os oito bairros foram criados entre 1979 e 2008 mediante diversas iniciativas. Quatro desses bairros - o Residencial Irisville, Conjunto Madre Germana II, o Residencial Real Conquista e o Bairro Vila Fim Social - foram gerados e construídos por movimentos sociais, como a Federação Goiana de Inquilinos e Posseiros, o Movimento Luta pela Casa Própria-MLCP e o movimento de famílias organizadas e apoiadas por partidos e políticos independentes. Quanto aos outros bairros, dois nasceram com o apoio e negociação da prefeitura e os últimos dois se originaram de loteamentos de terras particulares. 


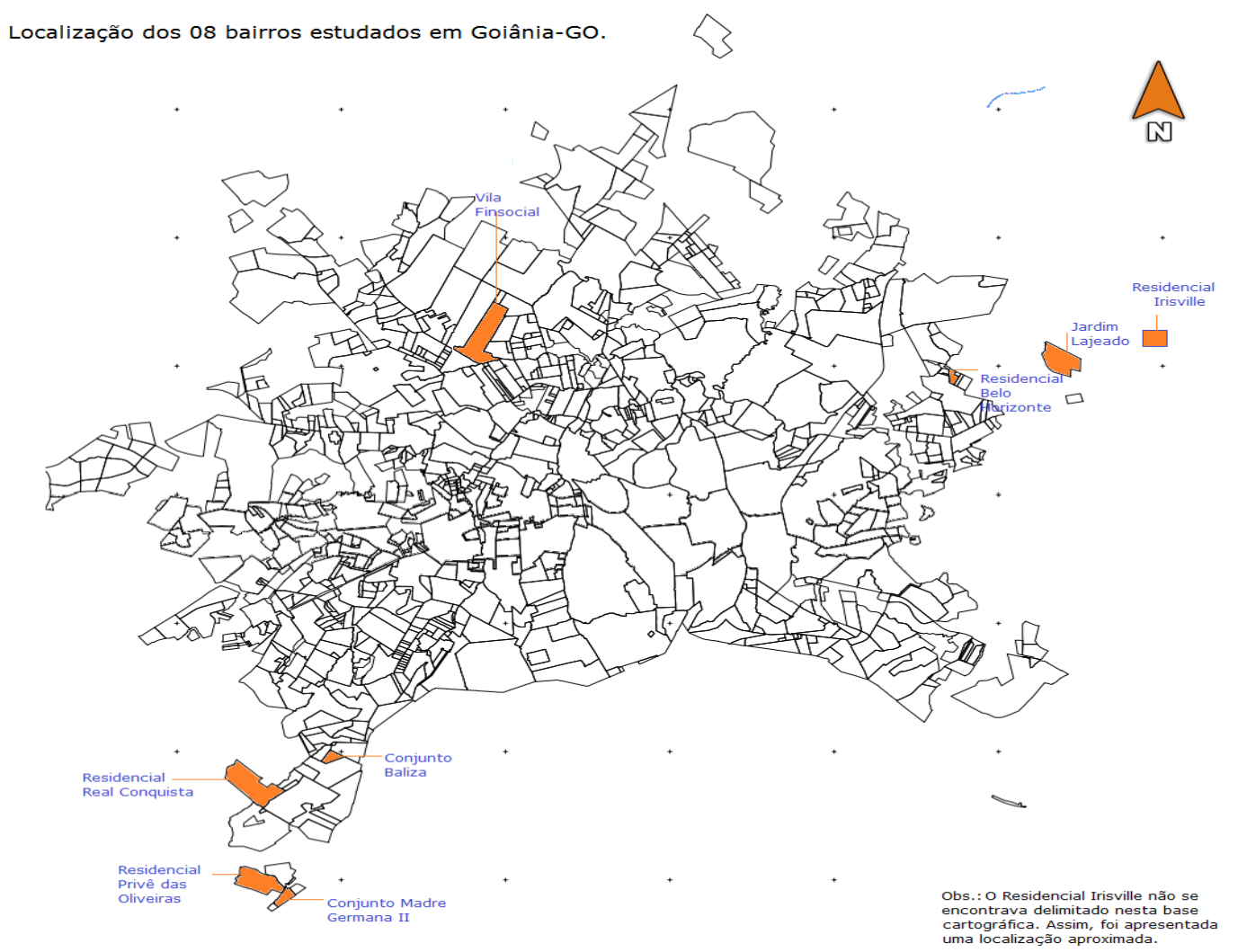

Figura 1. Localização dos oito bairros estudados, Goiânia (GO)

Fonte: Prefeitura Municipal de Goiânia, 2013. Elaborado por Cintia Godoi para a pesquisa.

Um aspecto adicional relevante sobre o conjunto desses bairros é a diversidade dos aspectos que as pessoas entrevistadas consideram como necessidade prioritária ou imediata. Embora a violência e a saúde fossem consideradas de maneira destacada como as principais necessidades, a educação, o saneamento básico, o transporte e o comércio local, entre outros, foram mencionados pelos entrevistados como prioridades socioambientais dos bairros, mostrando que existem deficiências e problemas diversos.

Para o desenvolvimento da pesquisa, assumiu-se como conceito de prioridades socioambientais os aspectos materiais e imateriais que determinam as condições de uma vida digna da população urbana e rural e que, portanto, devem ser atendidos e supridos em primeira instância ou de maneira prioritária. Entre outros, destacam-se a segurança pública; os serviços de água, o saneamento básico e a energia; os equipamentos e as instalações para a saúde; a educação, o lazer, bem como as vias de acesso, o transporte e o estado da regularização fundiária da terra que ocupam. Em termos ambientais, 
também é prioridade a resolução do manejo do lixo e dos riscos decorrentes da localização inadequada dos bairros e assentamentos em zonas afetadas por contaminações, inundações e desabamentos.

\section{A PROBLEMÁTICA E SUAS IMPLICAÇÕES TEÓRICAS}

Não existe bibliografia acerca do conceito de prioridades socioambientais. Na busca da sua definição e desenvolvimento, foram utilizadas três perspectivas de análise que permitem uma aproximação ao conceito. A primeira tem como base autores que exploram os conceitos de "desigualdade", "marginalidade urbana", "segregação urbana" ou "exclusão urbana", ou seja, que procuram explicar de maneira objetiva as condições de vida e as necessidades da população mais pobre e, nesta pesquisa, propõem-se como sendo as prioridades socioambientais. A segunda perspectiva é a atuação dos movimentos sociais na busca da moradia e a percepção subjetiva dos moradores dos bairros, aos quais lhes foram consultadas as suas três principais prioridades para melhorar suas condições urbanas de vida. E a terceira, parte das normas e diretrizes institucionais sobre a problemática urbana referente à garantia da satisfação das necessidades básicas e ao tratamento dos bairros e zonas pobres que devem ser prioritários.

A perspectiva de aproximação ao conceito de prioridades socioambientais, mediante a análise dos processos da "marginalidade urbana", "segregação urbana", "segmentação urbana" ou "exclusão urbana", tratada por diversos autores desde o início da urbanização, mostra que todas essas análises têm por propósito explicar a desigualdade social que se expressa objetivamente na cidade. Todos esses processos são a materialização da sociedade em formas desiguais de ocupação da terra, da qualidade da moradia e da disponibilidade dos serviços e equipamentos. As carências desses aspectos nos bairros pobres urbanos são as prioridades socioambientais.

Jean Lojkine (1979, p. 217) propõe metodologicamente, no contexto da "divisória entre as classes sociais no marco da urbanização", uma "análise de três tipos de segregação social e espacial": no nível da moradia; no nível dos equipamentos coletivos de educação, esportivos e sociais; e no nível do transporte. Para Baumann, vários processos urbanos continuarão acontecendo, 
a nova fragmentação do espaço da cidade, o encolhimento e desaparecimento do espaço público, a desintegração da comunidade urbana, a separação e segregação - e, acima de tudo, a extraterritorialidade da nova elite e a territorialidade forçada do resto (BAUMANN, 1999, p. 30-31).

Na mesma perspectiva, David Harvey, no trabalho $A$ liberdade da cidade, faz referência às desigualdades urbanas como um problema determinante nos conflitos sociais e afirma que "vivemos, na maioria, em cidades divididas, fragmentadas e tendentes ao conflito" (2013, p. 27). Para esse autor, a globalização e o neoliberalismo enfatizaram as desigualdades sociais ao invés de diminuí-las e os desenvolvimentos urbanos desiguais contribuem para o conflito social.

$\mathrm{Na}$ perspectiva subjetiva dos moradores dos bairros estudados, foram as necessidades objetivas e imediatas de moradia que motivaram e fizeram surgir os movimentos sociais. E, finalmente, esses movimentos pressionaram e lograram a criação dos oito bairros. Entretanto, no âmbito dos bairros já consolidados, as pessoas e os moradores entrevistados consideram de atenção prioritária a segurança pública, os equipamentos de saúde e educação, as redes de esgoto, o serviço de transporte, o comércio local de insumos domésticos básicos e os espaços públicos de lazer.

A discussão contemporânea mais relevante sobre os espaços urbanos está relacionada com o uso democrático do espaço público e do exercício dos direitos dos cidadãos de usufruir de forma igualitária os serviços e equipamentos da cidade. É no espaço público que se exerce a cidadania, a convivência e o lazer coletivo entre os cidadãos. Entretanto, esses espaços estão cada vez mais limitados ou não existem. Da mesma forma, as ruas são estreitas, escuras e estão em mau estado de conservação. E são esses os lugares públicos nos quais se desenvolve a insegurança e a violência, consideradas, por consenso, como a prioridade fundamental nos bairros pesquisados e em toda a cidade de Goiânia.

Com relação às normas e às diretrizes, a terceira perspectiva levantada nesta pesquisa, uma aproximação ao conceito de prioridades socioambientais se dá no Estatuto da Cidade (Lei $n^{0} 10.257$, de 10 de julho de 2001), que regulamenta os artigos 182 e 183 da Constituição Federal, no qual se propõe a criação de Zonas Especiais de Interesse Social-ZEIS, ou Áreas de Especial Interesse Social-AEIS, (Brasil, 2002, p. 
158). Essas zonas devem receber atenção prioritária nos planos diretores municipais e corresponderiam aos bairros pobres pesquisados em Goiânia.

O Estatuto da Cidade estabelece, nas suas diretrizes, o direito dos cidadãos à satisfação das necessidades básicas urbanas e nessa medida a falta ou deficiência de serviços e equipamentos básicos assumem a condição de prioridades socioambientais. A primeira diretriz do estatuto estabelece "garantia do direito a cidades sustentáveis, entendido como o direito à terra urbana, à moradia, ao saneamento ambiental, à infraestrutura urbana, ao transporte e aos serviços públicos, ao trabalho e ao lazer, para as presentes e futuras gerações" (BRASIL, 2001, p. 32).

Convém assinalar que foi Souza (2004) quem mais se aproximou do conceito de zonas prioritárias de atuação ao tratar da necessidade de zoneamento "includente" e zoneamento de prioridades. Esse autor discute e propõe a ideia do zoneamento "includente" partindo da identificação de áreas com necessidades básicas não resolvidas e, desse modo, fazer uma inversão de prioridades, favorecendo os bairros mais necessitados e não os bairros exclusivos que são sempre privilegiados pelas políticas públicas de serviços, equipamentos e infraestrutura.

\section{PROCEDIMENTOS METODOLÓGICOS}

Como procedimento metodológico, é fundamental que as prioridades socioambientais sejam estabelecidas pelos próprios habitantes e obtidas mediante uma pesquisa de opinião estatisticamente representativa ou qualificada ao se consultar pessoas-chave. São os moradores dos bairros e das localidades rurais os que vivenciam e conhecem objetivamente as necessidades em termos sociais e ambientais e, por esse motivo, devem ser consultados. Além disso, as prioridades não são as mesmas em todos os lugares nem para todos os habitantes e variam com o tempo e as circunstâncias.

Com relação aos procedimentos operacionais para realização da pesquisa nos bairros de Goiânia, apresenta-se, nesta seção, a forma pela qual se procedeu a escolha dos oito bairros; das pessoas-chave entrevistadas; e das perguntas formuladas e, também, como foi realizada a coleta e a sistematização da informação.

A seleção dos oito bairros mais pobres na cidade de Goiânia foi realizada com a colaboração do IMB, e foi feita considerando as 
deficiências das redes de serviços e a disponibilidade de equipamentos sociais. Os bairros selecionados foram os seguintes, em ordem alfabética: Conjunto Habitacional Baliza, Conjunto Madre Germana II, Jardim Lajeado; Residencial Belo Horizonte, Residencial Irisville, Residencial Privê das Oliveiras, Residencial Real Conquista e Vila Fim Social.

As pessoas-chave foram selecionadas de acordo com a liderança formal ou informal nos bairros pesquisados. Dessa forma, foram selecionados os líderes e os representantes comunitários e de associações do bairro; as lideranças religiosas; os membros de partidos políticos e os vereadores de bairro; os moradores e os comerciantes mais antigos; as lideranças do setor educativo local, como diretores e coordenadores de escolas; lideranças em saúde coletiva, principalmente médicos, enfermeiros e agentes de saúde; e outros representantes de grupos de moradores dos bairros. Os contatos iniciais foram realizados com as lideranças das associações de moradores e pessoas reconhecidas dessas localidades e esses contatos colaboraram ao indicar outras pessoas que atuaram na criação e na consolidação dos bairros e nas atuais atividades sociais.

As entrevistas foram realizadas por grupos de dois ou três alunos do Mestrado em Desenvolvimento Regional das Faculdades Alfa com base em um formulário no qual se indagou:

a) a origem do bairro e a forma pela qual foi implantado;

b) como é e foi a organização comunitária e a participação social nas iniciativas e nas obras no bairro; e

c) a enumeração de forma hierárquica das três principais prioridades socioambientais em cada bairro.

O formulário incluiu, também, perguntas específicas sobre a condição de cada um dos serviços públicos, dos equipamentos sociais e problemas relacionados com o manejo dos resíduos e os riscos ambientais. Com base nas respostas dos entrevistados, estabeleceu-se uma sistematização hierárquica das prioridades de cada bairro e, assim, do conjunto desses.

No total, foram realizadas 80 entrevistas com as pessoas-chave, dez em cada bairro. A inserção na comunidade e o grau de conhecimento das problemáticas socioambientais dos bairros desses entrevistados garantiram uma informação de alta veracidade. Com essas pessoas se estabeleceu um diálogo aberto e sem restrições, uma vez 
que elas se mostraram interessadas em facilitar o conhecimento da situação social, os conflitos e as necessidades do bairro.

A sistematização da pesquisa de campo, apresentada neste artigo, corresponde a uma tabulação das respostas fornecidas. Ao se consultar os entrevistados sobre quais seriam as três principais prioridades, obteve-se como resultado 20 necessidades ou problemas indicados como prioritários. E, em seguida, ao sistematizar as respostas, considerando somente as três prioridades mais mencionadas em cada bairro, o total de aspectos assinalados diminuiu para 11 prioridades. Como podem ser verificados na seção seguinte, sobre os resultados da pesquisa, os problemas mencionados pelos entrevistados são diversos e mostram que não existe consenso, embora a segurança e a saúde se destaquem como prioridades nos bairros pesquisados.

\section{BREVE HISTÓRICO DO DESENVOLVIMENTO URBANO DESIGUAL DE GOIÂNIA}

A construção de Goiânia como nova capital do Estado de Goiás foi uma ideia discutida desde o Império e a República e, em torno dessa mudança de sitio, existem diversos argumentos que incluem as dificuldades econômicas decorrentes da queda da produção de ouro nos garimpos da antiga capital Vila Boa, hoje cidade de Goiás, da falta de perspectivas de desenvolvimento econômico dessa região e dos interesses políticos diferentes aos das elites residentes nessa antiga capital.

Para Borges, "A cidade de Goiânia nasceu de ideais que associavam cada vez mais a concepção de cidade capital com crescimento econômico regional", (2012, p.44). No trabalho "Goiânia: a Capital do Sertão", Chaul afirma, com referência à antiga capital que "As deficiências gerais da capital não passaram despercebidas, e as críticas se acirravam tentando denotar a falta de requisitos básicos para se manter em Vila Boa uma capital representativa" (1997, p.7).

Foram diversos os aspectos que exigiam a mudança da capital de Goiás, sendo que a luta política pelo poder no estado tornou a construção da nova capital uma bandeira e instrumento de confronto entre a antiga elite regional e Ludovico Teixeira, que, como interventor nomeado por Getúlio Vargas em 1930, assumiu a fundação e a transferência da nova capital Goiânia. Segundo Gomide (2002, p.25), 
"para Pedro Ludovico Teixeira, que desejava se tornar mais forte politicamente, mudar a capital era construir um espaço novo, no qual ele poderia administrar, sem tantas influências dos políticos fortes do passado".

Em dezembro de 1932, foi nomeada uma comissão para seleção do lugar da construção da nova capital e, em maio de 1933, Pedro Ludovico assinou o decreto que estabeleceu as bases para a construção da que seria, segundo suas próprias palavras, uma "capital acessível, que irradiasse progresso e marchasse na vanguarda, coordenando a vida política e estimulando a econômica, ligada à maioria dos municípios por uma rede rodoviária planificada" (apud CHAUL, 1997, p. 16). Foi elaborado um plano urbano para uma cidade de 50.000 habitantes e, assim, a cidade de Goiânia foi inaugurada oficialmente em julho de 1942, por Pedro Ludovico, que ainda era interventor, cargo que ocupou até 1945. Ludovico foi, em seguida, eleito governador (de 1951 a 1954).

A urbanização do Município de Goiânia foi acelerada. Em 1940, a população urbana era de 18.889 habitantes e representavam 39\% da população planejada e, em 1950, ascendeu para 40.333, representando $76 \%$ da população prevista no plano (Tabela 1). O crescimento foi de $230 \%$ em uma década. Como esse número de habitantes indica, o processo de migração e de urbanização era acelerado. Assim, o plano urbano para 50.000 pessoas foi superado em poucos anos. O maior crescimento urbano de Goiânia ocorreu na década de 1950, devido, sobretudo, a que o código de edificações, que regulamentava o zoneamento, o loteamento e o uso e ocupação do solo, e impunha obrigações aos urbanizadores de implantação de infraestrutura básica, incluindo ruas, calçamento, água, esgoto e energia elétrica não foi mais exigido pelo governo sob pressão dos urbanizadores. Dessa forma, os proprietários dos terrenos limítrofes às áreas urbanizadas do plano original de Goiânia e os especuladores imobiliários conseguiram implantar novos loteamentos de forma rápida e sem especificações técnicas urbanas. É a partir desse momento que se inicia o processo de urbanização desordenada da cidade e, apesar das tentativas institucionais de ordenar a expansão urbana, a cidade foi desbordada, chegando ao atual momento no qual existe uma drástica desigualdade e segregação social na estrutura urbana. 
Tabela 1. Evolução da população rural e urbana do Município de Goiânia entre 1940 e 2010

\begin{tabular}{c|c|c}
\hline Ano & População urbana (\%) & População rural (\%) \\
\hline 1940 & 39 & 61 \\
\hline 1950 & 76 & 24 \\
\hline 1960 & 45 & 55 \\
\hline 1970 & 56 & 44 \\
\hline 1980 & 67 & 33 \\
\hline 1990 & 76 & 24 \\
\hline 2000 & 81 & 19 \\
\hline 2006 & 83 & 17 \\
\hline 2010 & 84,35 & 15,65 \\
\hline
\end{tabular}

Fonte: IBGE. Anuário Estatístico do Brasil, 1986, 1990, 1993 e 1997; Censos demográficos de 2000 e 2010; Síntese de Indicadores Sociais, 2007.

A expansão de Goiânia foi incentivada pela chegada da ferrovia desde São Paulo em 1951, pela construção de Brasília em 1956-1960, pela construção da rodovia que liga a cidade a São Paulo no final da década de 1950 pela construção de hidrelétricas e universidades. Nas décadas seguintes, de 1960 a 1970, a urbanização acelerada continuou, dessa vez, estimulada pela ocupação do cerrado com a expansão do agronegócio. O crescimento da cidade na década de 1980 foi proporcionalmente menor, contudo, no início da década de 1990, a população do Município de Goiânia já chegava a 920.840 habitantes. O Censo Demográfico do IBGE de 2010 indicou que o Município de Goiânia tinha 1.302.001 habitantes e a projeção para 2014 foi de 1.430 .697 habitantes.

O crescimento demográfico e a urbanização do território do Município de Goiânia fizeram com que os municípios vizinhos sofressem o mesmo efeito. Atualmente, eles estão conurbados, integrando a Região Metropolitana de Goiânia desde 1999, com 13 municípios. Em março de 2010, mais sete municípios foram integrados à região, totalizando 20 municípios e população metropolitana de 2.335.609 habitantes.

\section{ORIGEM E ORGANIZAÇÃO SOCIAL NOS BAIRROS PESQUISADOS}

Com relação às origens e ao desenvolvimento dos bairros analisados, o Quadro 1, a seguir, mostra a diversidade das iniciativas 
promotoras. Quatro desses bairros foram gerados por movimentos sociais, dois nasceram por apoio e negociação da prefeitura e dois restantes se originaram pelas iniciativas de loteamentos de terras particulares. 


\begin{tabular}{|c|c|c|}
\hline Nome do Bairro & Iniciativa de Criação & Organização social \\
\hline $\begin{array}{c}\text { Conjunto Habitacional } \\
\text { Baliza }\end{array}$ & $\begin{array}{l}\text { Terreno adquirido em } 1992 \\
\text { pela prefeitura e entrega de } \\
\text { lotes aos servidores públicos. }\end{array}$ & $\begin{array}{l}\text { Existiu uma organização } \\
\text { coletiva no início do bairro, } \\
\text { mas hoje não existe mais. }\end{array}$ \\
\hline Residencial Irisville & $\begin{array}{c}\text { Iniciativa popular que junto à } \\
\text { prefeitura criaram uma } \\
\text { cooperativa em } 2008 .\end{array}$ & $\begin{array}{c}\text { A cooperativa fortaleceu a } \\
\text { união entre os moradores e } \\
\text { se mantém ativa } \\
\text { atualmente. }\end{array}$ \\
\hline Bairro Jardim Lajeado & $\begin{array}{l}\text { Proprietários negociaram com } \\
\text { a prefeitura a entrega de } \\
\text { terrenos a câmbio de } \\
\text { benfeitorias em outras áreas a } \\
\text { serem urbanizadas em } 1983 .\end{array}$ & $\begin{array}{l}\text { A organização social do } \\
\text { bairro sempre existiu e nos } \\
\text { dias atuais é muito influente } \\
\text { na realização de projetos } \\
\text { em benefício da } \\
\text { comunidade. }\end{array}$ \\
\hline $\begin{array}{l}\text { Conjunto Madre } \\
\text { Germana II }\end{array}$ & $\begin{array}{l}\text { O Movimento de Luta pela } \\
\text { Casa Própria (MLCP) recebeu } \\
\text { apoio da prefeitura e de } \\
\text { vereadores em } 1996 \text { para } \\
\text { ocupar os terrenos } \\
\text { negociados. }\end{array}$ & $\begin{array}{c}\text { A Associação dos Moradores } \\
\text { promove diversas atividades } \\
\text { para manter a unidade do } \\
\text { bairro e tem } \\
\text { reconhecimento social. }\end{array}$ \\
\hline $\begin{array}{c}\text { Residencial Belo } \\
\text { Horizonte }\end{array}$ & $\begin{array}{c}\text { Loteamento de uma } \\
\text { imobiliária privada em } 1994 .\end{array}$ & $\begin{array}{c}\text { A Associação dos Moradores } \\
\text { do bairro é bem ativa. }\end{array}$ \\
\hline $\begin{array}{l}\text { Residencial Privê das } \\
\text { Oliveiras }\end{array}$ & $\begin{array}{l}\text { Loteamento privado de terras } \\
\text { da fazenda Dourados na } \\
\text { fronteira da urbanização de } \\
\text { Goiânia em } 1990 .\end{array}$ & $\begin{array}{l}\text { Nunca existiu organização } \\
\text { social no bairro e não há } \\
\text { iniciativas populares para } \\
\text { resolver as diversas } \\
\text { necessidades. }\end{array}$ \\
\hline $\begin{array}{l}\text { Residencial Real } \\
\text { Conquista }\end{array}$ & $\begin{array}{l}\text { Maior invasão urbana de } \\
\text { Goiás em } 2004 .\end{array}$ & $\begin{array}{l}\text { Houve divisão entre as } \\
\text { lideranças, mas as atuais } \\
\text { são bem ativas e têm o } \\
\text { reconhecimento do bairro. }\end{array}$ \\
\hline Bairro Fim Social & $\begin{array}{c}\text { Invasão da fazenda Caveirinha } \\
\text { em } 1982 .\end{array}$ & $\begin{array}{l}\text { Inicialmente a organização } \\
\text { foi muito forte na criação e } \\
\text { consolidação do bairro. }\end{array}$ \\
\hline
\end{tabular}

Quadro 1.Iniciativas que deram origem aos bairros e suas organizações sociais Fonte: Pesquisa de campo com os alunos de Mestrado da Alfa.

De acordo com os relatos dos entrevistados, as organizações sociais têm diversas trajetórias históricas de desenvolvimento e de consolidação. Em geral, pode-se afirmar que os bairros, nos quais houve uma luta maior para serem implantados e consolidados, conseguiram manter uma organização social e comunitária forte. Com base nessa organização e com trabalho em mutirão, construíram redes 
de serviços básicos, como a coleta de lixo, e alguns equipamentos como escolas, sedes de reunião dos moradores e, ainda, promoveram linhas de transporte para essas localidades.

É o caso do Residencial Real Conquista, por exemplo, que é produto da desocupação violenta da maior invasão urbana ocorrida em Goiás, em 2005, de um terreno que foi entregue à especulação em 2004 no Setor Oeste Industrial. (LACERDA, 2013, p. 133). A organização social dos moradores do Real Conquista se destaca pela sua persistência e solidez, já que a sua luta pela moradia somente veio a ser resolvida no ano de 2013, com o reassentamento dos moradores no bairro construído, por etapas na periferia, na região Sudoeste de Goiânia, por diversas instituições públicas. A associação dos moradores já conseguiu estabelecer uma rotina na coleta do lixo e levar linhas de ônibus que não existiam.

No outro extremo, encontra-se o Residencial Privê das Oliveiras. Trata-se de um loteamento privado e um bairro no qual a organização dos moradores nunca foi promovida nem existiu e esta pesquisa demonstrou ser o bairro com as maiores necessidades e prioridades socioambientais. Nesse sentido, é possível afirmar que quanto maior for a luta pela terra, mais forte serão as organizações dos moradores. Em consequência, com essa base estabelecida, as organizações conseguem satisfazer de maneira autônoma as necessidades de serviços e equipamentos da comunidade, bem como reivindicar de forma organizada ante o Estado o que essas comunidades locais consideram como suas prioridades socioambientais.

$\mathrm{Na}$ perspectiva da constatação de processos de diferenciação social e das possibilidades de avançar nas reivindicações dos movimentos sociais para a melhoria das suas condições de vida, Paulo Krischke (1979, p. 44) afirma que: "estas tendências dispares estão inter-relacionadas com o acesso diferenciado dos moradores às oportunidades organizacionais e aos resultados das reivindicações comunitárias". Nas análises dos oito bairros de Goiânia, foi constatado que as associações dos moradores são um instrumento fundamental para fortalecer a organização social local, reclamar de forma organizada e consolidar as reivindicações comunitárias para obter maiores resultados das demandas ante as instituições do Estado. Na Tabela 2, apresenta-se a população e os equipamentos de educação e saúde nos oito bairros. Pode ser observado que nem todos os bairros dispõem 
dessas instalações e que não existe racionalidade nem coerência entre a população e o número de centros instalados de educação infantil, das escolas da rede municipal e estadual, dos Centros de Atenção Integral à Saúde (CAIS), as Unidades de Atenção Básica a Saúde da Família (UABSF) e as quadras de esportes. Ficam evidentes as deficiências e a desigualdade dos equipamentos disponíveis entre os próprios bairros pobres, sendo muito maiores ainda as desigualdades com os bairros ricos, que, na maioria, dispõem de escolas e colégios privados muito melhor equipados. Cabe mencionar que das 28 quadras esportivas existentes em Goiânia nenhuma delas está localizada nos oito bairros estudados na pesquisa.

Tabela 2. População e equipamentos sociais nos bairros pesquisados

\begin{tabular}{|c|c|c|c|c|c|c|}
\hline Bairros & $\begin{array}{l}\text { População } \\
\text { (total) }\end{array}$ & $\begin{array}{c}\text { Centros } \\
\text { Educação } \\
\text { Infantil }\end{array}$ & $\begin{array}{c}\text { Escolas } \\
\text { Municipais }\end{array}$ & $\begin{array}{l}\text { Escolas } \\
\text { Estaduais }\end{array}$ & $\begin{array}{l}\text { Unidades } \\
\text { de Saúde }\end{array}$ & $\begin{array}{c}\text { Quadras } \\
\text { de } \\
\text { Esportes }\end{array}$ \\
\hline $\begin{array}{l}\text { Conjunto } \\
\text { Habitacional } \\
\text { Baliza }\end{array}$ & 818 & & 1 & & & \\
\hline $\begin{array}{l}\text { Residencial } \\
\text { Irisville }\end{array}$ & 1.965 & & & & & \\
\hline $\begin{array}{l}\text { Bairro Jardim } \\
\text { Lajeado }\end{array}$ & 643 & & & 1 & & \\
\hline $\begin{array}{l}\text { Conjunto Madre } \\
\text { Germana II }\end{array}$ & 15.000 & & & & 1 UABSF & \\
\hline $\begin{array}{l}\text { Residencial Belo } \\
\text { Horizonte }\end{array}$ & 478 & & & & & \\
\hline $\begin{array}{l}\text { Residencial Privê } \\
\text { das Oliveiras }\end{array}$ & 387 & & & & & \\
\hline $\begin{array}{l}\text { Residencial Real } \\
\text { Conquista }\end{array}$ & 5.217 & & 1 & & 1 UABSF & \\
\hline Bairro Fim Social & 16.971 & 1 & 2 & 1 & $\begin{array}{l}1 \text { CAIS } \\
5 \text { UABSF }\end{array}$ & \\
\hline
\end{tabular}

Fonte: Secretarias da Prefeitura de Goiânia. 2013.

Com base em informações da Empresa da Rede Metropolitana de Transporte Coletivo de Goiânia-RMTC, ver Tabela 3 a seguir, é possível visualizar as desigualdades dos serviços de transporte entre os bairros, sendo que os mais periféricos (ver Figura 1) contam com o menor número de linhas de ônibus. Ou seja, quanto mais afastado e isolado o bairro, maior a dificuldade de transporte dessa população. 
Tabela 3. Linhas de transporte nos bairros

\begin{tabular}{l|c}
\hline \multicolumn{1}{c|}{ Nome do Bairro } & Número de Linhas \\
\hline Conjunto Habitacional Baliza & 2 \\
\hline Residencial Irisville & 1 \\
\hline Bairro Jardim Lajeado & 4 \\
\hline Conjunto Madre Germana II & 1 \\
\hline Residencial Belo Horizonte & 2 \\
\hline Residencial Privê das Oliveiras & 1 \\
\hline Residencial Real Conquista & 1 \\
\hline Bairro Vila Fim Social & 7 \\
\hline
\end{tabular}

Fonte: Empresa da Rede Metropolitana de Transporte Coletivo de Goiânia 2014.

\section{DEFINIÇÃO DAS PRIORIDADES PELA POPULAÇÃO}

As prioridades estabelecidas pelos entrevistados nos bairros foram sistematizadas na Tabela 4, com base nas respostas fornecidas, integrando 20 aspectos considerados pelos moradores como as principais necessidades dessas localidades. Na tabela, pode-se verificar que um aspecto relevante das prioridades socioambientais é a diversidade de opiniões sobre o que os moradores consideram como prioritário ou urgente nos seus bairros, sendo que a segurança pública e a saúde se encontram nos dois primeiros lugares de prioridade, com $20,41 \%$ e $17,91 \%$ das respostas, e a educação e o esgoto no terceiro e quarto lugar com $10,83 \%$ e $10,0 \%$, respectivamente. 
Tabela 4. Prioridades socioambientais de acordo com os moradores dos bairros

\begin{tabular}{|c|c|c|c|c|c|c|c|c|c|c|c|}
\hline \multirow{2}{*}{\multicolumn{2}{|c|}{$\begin{array}{l}\text { Bairros } \\
\text { Prioridades }\end{array}$}} & \multirow{3}{*}{$\begin{array}{c}\text { Baliza } \\
5 \\
\end{array}$} & \multirow{3}{*}{$\begin{array}{c}\text { Irisville } \\
2 \\
\end{array}$} & \multirow{3}{*}{$\begin{array}{c}\text { Lajeado } \\
6 \\
\end{array}$} & \multirow{3}{*}{$\begin{array}{c}\text { Germana } \\
5 \\
\end{array}$} & \multirow{3}{*}{\begin{tabular}{|c} 
Belo \\
Horizonte \\
10
\end{tabular}} & \multirow{3}{*}{$\begin{array}{c}\begin{array}{c}\text { Privê } \\
\text { Oliveiras }\end{array} \\
7 \\
\end{array}$} & \multirow{3}{*}{$\begin{array}{c}\begin{array}{c}\text { Real } \\
\text { Conquista }\end{array} \\
7 \\
\end{array}$} & \multirow{3}{*}{$\begin{array}{c}\begin{array}{c}\text { Fim } \\
\text { Social }\end{array} \\
7 \\
\end{array}$} & \multirow{3}{*}{$\begin{array}{c}\text { Respostas } \\
\text { (total) } \\
49\end{array}$} & \multirow{3}{*}{$\begin{array}{c}\begin{array}{c}\text { Total } \\
(\%)\end{array} \\
20,4 \\
\end{array}$} \\
\hline & & & & & & & & & & & \\
\hline 1 & Segurança pública & & & & & & & & & & \\
\hline 2 & Saúde & 2 & 7 & 3 & 8 & 8 & 1 & 9 & 5 & 43 & 17,9 \\
\hline 3 & Educação & 1 & 5 & 2 & 10 & 1 & 2 & 5 & & 26 & 10,8 \\
\hline 4 & Rede de esgoto & 6 & - & 7 & - & 4 & 1 & - & 6 & 24 & 10,0 \\
\hline 5 & Transporte & 4 & - & 1 & - & 6 & 2 & - & 1 & 14 & 5,83 \\
\hline 6 & Comércio local, supermercado & 5 & 8 & - & - & - & - & - & - & 13 & 5,41 \\
\hline 7 & Lazer & - & 1 & - & 5 & - & - & 1 & 4 & 11 & 4,58 \\
\hline 8 & Creches & - & - & 5 & 2 & - & - & 1 & 1 & 9 & 3,75 \\
\hline 9 & Energia, iluminação pública & 1 & - & 1 & - & 1 & 4 & - & 1 & 8 & 3,33 \\
\hline 9 & Coleta de lixo, limpeza urbana & 5 & - & - & - & - & 1 & - & 1 & 8 & 3,33 \\
\hline 10 & Regularização fundiária & - & - & 2 & - & - & 2 & - & 3 & 7 & 2,91 \\
\hline 11 & Combate ao tráfico de drogas & 1 & - & - & - & - & - & 5 & - & 6 & 2,50 \\
\hline 12 & Urbanização & - & - & - & - & - & 4 & 1 & - & 5 & 2,08 \\
\hline 12 & Rede de água & - & - & - & - & - & 5 & - & - & 5 & 2,08 \\
\hline 12 & Telefone, orelhão & - & 5 & - & - & - & - & - & - & 5 & 2,08 \\
\hline 13 & Projetos sociais, juventude & - & 1 & - & - & - & - & 1 & - & 2 & 0,83 \\
\hline 13 & $\begin{array}{l}\text { Instalação de lotérica ou } \\
\text { banco }\end{array}$ & - & - & 2 & - & - & - & - & - & 2 & 0,83 \\
\hline 14 & Emprego & - & - & 1 & - & - & - & - & - & 1 & 0,41 \\
\hline 14 & Praça pública & - & - & - & - & - & 1 & - & - & 1 & 0,41 \\
\hline 14 & Igreja & - & 1 & - & - & - & - & - & - & 1 & 0,41 \\
\hline
\end{tabular}


Fernando Negret Fernandez, Elimar Pinheiro do Nascimento

\begin{tabular}{|l|l|l|l|l|l|l|l|l|l|l|}
\hline Total & 30 & 30 & 30 & 30 & 30 & 30 & 30 & 30 & 240 & 100,0 \\
\hline
\end{tabular}

Observação: Os dados contidos nesta tabela correspondem às respostas fornecidas pelos entrevistados. 
As outras prioridades foram mencionadas menos vezes, porém, com frequências mais aproximadas entre elas. Ao serem considerados somente os três aspectos que tiveram maior menção em cada bairro, o total de prioridades diminui para 11 , sendo que, neste caso, não ocorrem mudanças significativas na ordem hierárquica das prioridades, mas, sim, um incremento relevante das porcentagens das duas primeiras prioridades. Nesse sentido, a segurança pública cresce para $26.85 \%$ das respostas, a saúde para $21,14 \%$, já a educação para $11,41 \%$ e a rede de esgoto para $10,85 \%$. Outro aspecto que se pode verificar no quadro, além da diversidade de prioridades, é que algumas necessidades são específicas de poucos bairros, devido às características sociais da população, à localização na estrutura urbana de Goiânia, à forma de ocupação do terreno, bem como, à disponibilidade de serviços públicos, de equipamentos e nível da urbanização.

Igualmente, verificou-se que a segurança pública foi mencionada efetivamente em todos os bairros com uma alta frequência de indicação de prioridade, o que demonstra ser o principal problema, comum a todos os bairros. Os entrevistados se referem a uma deficiente presença policial e rondas apenas esporádicas, que não resolvem o alto índice de criminalidade e violência nos bairros. Também mencionaram a relação da insegurança entre o tráfico de drogas e os jovens e os adolescentes.

De acordo com o anuário estatístico de Goiânia de 2012, houve um grande aumento das ocorrências de delitos na cidade entre 2010 e 2011 . O homicídio doloso aumentou 54,6\%, passando de 268 para 414 ocorrências; a tentativa de homicídios, 34,2\%, de 719 a 965 ocorrências, o roubo a estabelecimentos comerciais, 120,5\%; passou de 525 para 1.158 ocorrências; o roubo a transeuntes aumentou $49,4 \%$, de 4.409 para 6.586 ocorrências; e o roubo a residências cresceu $63,8 \%$, indo de 130 para 213 delitos.

A saúde é a segunda prioridade em todos os bairros, sendo mencionada em alguns bairros com maior frequência do que em outros. As deficiências no serviço, segundo os moradores, ocorrem pela falta de postos de atendimento e de médicos, bem como pela distância aos estabelecimentos nos quais a população geralmente é atendida. Nesses lugares, a demanda supera a capacidade de atendimento dos pacientes. Nos períodos de surto de dengue, por exemplo, que anualmente se 
mostram mais intensos, os postos de saúde recebem um número de consultas ainda mais numeroso, tornando o atendimento mais demorado e precário.

A terceira prioridade é a educação, sendo que a deficiência do serviço educativo é entendida pelos moradores como a falta de colégios e escolas nos seus bairros, bem como a falta de vagas. Estas deficiências obrigam as crianças e jovens e se deslocarem a grandes distâncias dos seus bairros de residência, ocasionando enormes esforços físicos e, em consequência, desmotivação pelo estudo e abandono das aulas, além dos custos de transporte que muitas destas famílias pobres não têm condições de pagar.

A falta de rede de esgoto é a quarta prioridade mencionada com alta frequência por cinco bairros. Nos relatos realizados pelos entrevistados, afirma-se que as fossas sépticas existentes em todos os bairros não são soluções adequadas e são fontes de contaminação do lençol freático. Além disso, causam odores, reprodução de vetores de doenças e vazamentos nas calçadas em períodos de chuvas com graves riscos para a saúde. Cabe assinalar que nenhum dos bairros conta com rede de coleta e tratamento de esgoto. Entretanto, o saneamento somente foi assinalado como principal prioridade no conjunto das respostas em dois dos bairros pesquisados.

O transporte deficiente é um problema que ocupa o quinto lugar de prioridade pelas respostas de cinco bairros. Os entrevistados relataram que são poucas as linhas de ônibus que servem esses bairros, afetando, principalmente, os trabalhadores da periferia que não contam com vale transporte e todos aqueles que precisam se deslocar por diversas atividades da vida cotidiana.

As dificuldades de abastecimento de bens e serviços nos bairros mais periféricos e isolados levaram os moradores de duas comunidades estudadas a determinar a falta de estabelecimentos de comércio, também em quinto lugar de prioridade, no conjunto global das reivindicações. De fato, o isolamento e a necessidade de ter que se deslocar para adquirir os bens de uso cotidiano é um incômodo e perda de tempo que afeta de maneira grave as condições de vida da população desses bairros.

O lazer ficou em sexta posição como outro problema de atenção prioritária, segundo moradores de quatro bairros, sendo para dois 
desses uma reivindicação de alta prioridade. A falta de opções de lazer é percebida pelos moradores como a inexistência de parques, áreas verdes e espaços para a prática de esportes.

É importante ressaltar que as creches foram consideradas a sétima prioridade, principalmente, porque as mães também trabalham fora de casa para ajudar com os gastos do lar. Essas creches são espaços essenciais para que as crianças mais novas tenham onde ficar em segurança enquanto seus pais trabalham.

Duas análises complementares foram realizadas sobre as prioridades assinaladas pelos entrevistados: uma com relação ao tipo de iniciativa de criação dos bairros, seja de movimentos sociais, da prefeitura e da iniciativa privada, e a outra análise sobre a reivindicação dos moradores e a existência nos bairros de equipamentos de saúde, educação, lazer e transporte público.

Constatou-se que nos bairros de origem nos movimentos populares, Irisville, Madre Germana, Real Conquista e Fim Social, a segurança não é a primeira prioridade nos três primeiros, mas, sim, no último. Vale destacar que segurança é a segunda prioridade no Germana e no Real Conquista. As prioridades para os entrevistados em Irisville, Madre Germana e Real Conquista são comércio, educação e saúde e estas reivindicações coincidem com a não existência destes equipamentos nos bairros.

As duas primeiras prioridades nos bairros criados com apoio da prefeitura, Baliza e Lajeado, são rede de esgoto e segurança, além de comércio no primeiro e creches no segundo. Esses dois bairros não mencionaram saúde e educação como alta prioridade, pois dispõem de instalações desses equipamentos. O Baliza assinalou em terceiro lugar o comércio, devido ao seu isolamento, e o Lajeado as creches, sendo de todos os bairros o que mais prioridade assinou a este equipamento para as crianças.

Por último, os dois bairros que surgiram da iniciativa privada, Belo Horizonte e Privê das Oliveiras, assinalaram com alta prioridade a segurança, seguida por saúde e transporte, no primeiro bairro, e por água, energia e urbanização, no segundo.

Dessas análises, ressalta-se que os bairros oriundos dos movimentos sociais não assinalaram com tanta intensidade a segurança como prioridade, entretanto, os da iniciativa privada e da prefeitura, 
sim. Embora seja a prioridade destacada pelo conjunto dos oito bairros, essa diferença pode ser resultado da unidade dos moradores que, mantendo laços de amizade e solidariedade, ainda conseguem lutar contra a insegurança.

\section{ANÁLISE DOS RESULTADOS}

O desenvolvimento acelerado e desordenado de Goiânia, particularmente após serem desbordados os limites do plano original da cidade, teve a sua expansão sem controle a partir da permissão institucional de loteamentos criados sem serviços ou equipamentos por empresas imobiliárias que pressionaram por tal medida. Mesmo assim, o déficit de moradias para as famílias pobres já assentadas em condições não dignas em Goiânia e suas imediações, além dos migrantes que chegaram após a fundação da cidade de diferentes lugares do Brasil para construir uma nova vida, constituíram movimentos sociais e uma grande pressão para a construção de bairros como os analisados nesta pesquisa.

Os bairros estudados têm diversas origens, entretanto em nenhum deles houve planejamento ou espaço suficiente destinado para a instalação de equipamentos sociais de saúde, educação, esporte e lazer que pudessem satisfazer as necessidades básicas e prioritárias de seus moradores. A luta pela moradia gerou diversos movimentos e modalidades de ocupação de territórios e construção de bairros, mas a urgência das famílias de um lugar onde construir, inicialmente, um barraco deu origens a bairros com deficiências em serviços e infraestrutura que ainda não foram resolvidas.

Em termos ambientais, as prioridades estão ligadas, particularmente, com a rede de esgoto sanitário, que foi inicialmente substituído por fossas sépticas mal construídas e que, atualmente, constituem um fator determinante de contaminação e doenças. Ainda na questão ambiental, com relação ao lixo doméstico, o problema está relacionado com a falta de educação ambiental e de responsabilidade comunitária de moradores dos bairros, que depositam os resíduos nos lotes vazios e próximos das moradias. Dessa forma, o lixo com plásticos e recipientes acumulam água e se transformam nos lugares de reprodução do mosquito da dengue, doença que tem chegado a altos 
níveis de incidência nesses bairros. Segundo o Informe Técnico Semanal da Dengue (GOIÂNIA, 2013), em outubro de 2013, a capital tinha atingido o recorde de 57.918 casos.

A insegurança pública e a violência foram consideradas como as prioridades sociais mais urgentes dos oito bairros e estão relacionadas diretamente com a falta de serviços básicos e equipamentos sociais assinalados como necessidades principais. É compreensível que a segurança conste como prioridade, uma vez que determina as condições de vida da população, particularmente dos jovens e adolescentes, assinalados como principais agentes da maior parte das ocorrências dos delitos. A falta de oportunidades de matrícula, de acesso e de permanência prazerosa nas escolas, bem como a carência de instalações para o esporte e o lazer são apontadas como fatores que contribuem para que os jovens usem drogas e se dediquem à delinquência para obtê-las.

Da mesma maneira, a falta da rede de coleta e tratamento de esgoto, de manejo e destino adequado do lixo e a carência de equipamentos de saúde e de linhas de transporte afetam e tornam a vida nesses bairros difícil e frustrante, também afetando o comportamento dos jovens e adolescentes. Essas deficiências e necessidades explicam, em boa medida, a violência nesses bairros e também fora deles, em toda a cidade.

\section{CONCLUSÕES}

As prioridades socioambientais tratadas neste estudo são as necessidades básicas insatisfeitas da população assentada nos bairros pesquisados, sendo que essas prioridades nem sempre são as mesmas para todos, nem têm caráter permanente. As prioridades mudam com o tempo e as circunstâncias e podem ser resolvidas por políticas públicas ou por iniciativas comunitárias até onde é possível o esforço coletivo das comunidades. Em outros casos, mudanças ambientais abruptas transformam negativamente as condições de vida.

A solução de algumas prioridades nesses bairros foi devida à pressão de milhares de famílias que reivindicaram e lutaram, inicialmente, pela terra, como prioridade fundamental para iniciar a construção das suas moradias e, em consequência, seus bairros. 
Posteriormente, pela construção coletiva e, em alguns casos, com ajuda de instituições do Estado, foram resolvidos alguns serviços básicos e equipamentos sociais, entretanto, e como foi visto, ainda existem diversas prioridades que estão sendo reivindicadas.

A pesquisa nos bairros de Goiânia mostra que a luta pela moradia gerou diversos movimentos sociais urbanos, parcerias e formas diversas de ocupação da terra e da construção e consolidação de bairros a partir de meritórias lutas e esforços dos ocupantes e moradores. Pode-se afirmar que, quanto mais intensa foi a luta das famílias pela terra e pela moradia, mais sólidas e permanentes são as organizações comunitárias, que assumiram resolver algumas prioridades e o conseguiram, bem como reivindicar ao Estado aquelas ainda pendentes de maneira organizada e sistemática. Desse modo, cabe ressaltar a importância das organizações sociais para se atingir objetivos na resolução das suas prioridades socioambientais.

É necessário reiterar que a prioridade fundamental nos bairros, demonstrada pelas entrevistas, é a segurança pública, a luta contra a violência, e que, não obstante o confronto dos próprios moradores contra esse fenômeno, não têm conseguido resolvê-lo dada a sua intensidade e crescimento. Como foi visto, ainda são muitas as necessidades básicas não atendidas que afetam a toda a população e, particularmente, os jovens e adolescentes acusados pelos moradores dos bairros como os principais agentes de insegurança e violência. Nesse sentido, somente com a solução das necessidades prioritárias desses bairros e das dos jovens, por meio de melhores condições de acesso e permanência nas escolas de maneira satisfatória e prazerosa, da construção de espaços públicos para a participação cidadã, da realização de atividades culturais, esportivas e de lazer e do exercício da cidadania, será possível avançar na luta contra a violência e a insegurança, bem como na edificação de uma convivência social democrática. 


\section{REFERÊNCIAS}

BAUMANN, Zygmunt. Globalização, as consequências humanas. Rio de Janeiro: Jorge Zahar Editor, 1999.

BORGES, Darlene Limongi. Entre Muros de Sonhos e Sombras: um estudo sobre condomínios horizontais em Goiânia (1978-2005). Goiânia: Universidade Católica de Goiânia, 2012.

BRASIL. Estatuto da cidade: guia para implantação pelos municípios e cidadãos: Lei $\mathrm{n}^{\circ}$ 10.257, de 10 de julho de 2001, que estabelece diretrizes gerais da política urbana. Brasília: Câmara dos Deputados, Coordenação de Publicações, 2001.

CHAUL, N. N. F. Goiânia: a Capital do Sertão. Goiânia: Cidade Pensada. Edição UFG, 1997.

BRASIL. Estatuto da Cidade. Senado Federal. Brasília, 2002.

GOIÂNIA. Anuário estatístico de Goiânia. Goiânia: Secretaria Municipal de Planejamento e Urbanismo (SEPLAM), 2012. Disponível em: <http://www.goiania.go.gov.br/shtml/seplam/anuario2012/anuario.ht $\mathrm{ml}>$. Acessado em: maio de 2014.

GOIÂNIA. Informe Técnico Semanal Dengue. Goiânia: Secretária de Saúde, n. 215, out. 2013.

GOMIDE, Cristina Helou. História da Transferência da Capital: de Goiás para Goiânia. Histórias de Goiás. Goiânia: Universidade Estadual de Goiás, Agência Goiana de Cultura (AGEPEL), 2002.

HARVEY, David. A Liberdade da cidade. São Paulo: Boitempo Editorial, 2013.

KRISCHKE, Paulo José. A Igreja e as Crises Políticas no Brasil. Petrópolis: Editora Vozes, 1979. 
LACERDA, Carlos Felipe Ramalho. Residencial Real Conquista. In: Negret. F. Fernando. (Org.). Prioridades Socioambientais e Políticas Públicas em Goiânia, GO. Vila Velha, ES: Opção Editora, 2013.

LOJKINE, Jean. El Marxismo, el estado y la cuestión urbana. Siglo XXI Editores: México, 1979.

Mapa da Cidade de Goiânia e bairros estudados: Disponível em: <http://mapa.goiania.go.gov.br/siggoweb_net/>

SOUZA, Marcelo Lopes de. Mudar a Cidade: Uma introdução Crítica ao Planejamento e a Gestão Urbanos. 3. ed. Rio de Janeiro: Bertrand Brasil, 2004.

Submetido em 08/09/2014

Aprovado em 20/10/2015

Sobre os autores

Fernando Negret Fernandez

Pós-doutorando do Centro de Desenvolvimento Sustentável (CDS) da Universidade de Brasília (UnB). Professor e Pesquisador Faculdades Alfa.

Endereço: SQN 416, bloco J, apto 203, Brasília-DF, Brasil.

E-mail: fenegret@uol.com.br

Elimar Pinheiro do Nascimento

Sociólogo, Professor Associado do Centro de Desenvolvimento Sustentável - CDS da Universidade de Brasília - UnB.

Endereço: Centro de Desenvolvimento Sustentável (CDS), Campus Universitário Darcy Ribeiro, Gleba A, Asa Norte, Brasília-DF, Brasil.

E-mail: elimarcds@gmail.com 